\title{
Association Between Lung Function and Green Cover in the Living Space of School Children in Puducherry
}

\author{
D. Savita ${ }^{1 *}$ and V. Raji Sugumar ${ }^{2}$
}

\author{
1*Ph.D. Scholar, PG and Research Department of Home Science Bharathidasan Govt. College for Women, \\ (Autonomous), Puducherry, India; savitasanthosh@yahoo.com \\ 2Research Guide, PG and Research Department of Home Science Bharathidasan Govt. College for Women, \\ (Autonomous), Puducherry, India; rajis207@gmail.com
}

\begin{abstract}
Respiratory ailments such as cough, cold and allergies have been scaling up among children due to unprecedented decline in air quality during the past few decades in India. Respiratory health of children in Puducherry in association with air quality is not well documented. Peak Expiratory Flow Rate (PEFR), pulse rate and oxygen saturation (SPO2) were studied using peak flow meter and pulse oximeter in 1187 school children (10-14 years) selected from Puducherry by stratified random sampling method. Socio-demographic, health status, dietary and lifestyle pattern were collected by interview schedule. Children were categorized into two groups based on 'Yes' or 'No' answers for the presence of green space in and around their home. Data was analyzed using mean and standard deviation. Around $95 \%$ and $77.5 \%$ of the girls and $91.6 \%$ and $83.0 \%$ of the boys from rural and urban areas respectively had reported the presence of green cover in and around their homes. Girls living in the rural area (294.7 \pm 53.8 Vs. $297.2 \pm 49.9)$ and boys living in the urban area (291.9 \pm 68.5 Vs. $288.4 \pm 56.2)$ had higher PEFR when compared to their respective counterparts. The minimum $(2.8 \mathrm{~L} / \mathrm{min})$ and maximum difference $(23.9 \mathrm{~L} / \mathrm{min}$ ) in PEFR between the two groups was noted among urban girls and rural boys' respectively. Greenspaces lowers air pollution and increases the lung capacity. Hence, children must be encouraged to spend more time in greenspaces such as parks, backyards with more trees and plants and also motivated to start their own kitchen garden and terrace garden.
\end{abstract}

Keywords: School Children, Peak Expiratory Flow Rate, Peak Flow Meter, Pulse Oximeter, Union Territory of Puducherry

\section{Introduction}

Air quality which depends on air contamination has a pragmatic effect on every living organism on earth with a greater impact on mankind irrespective of age and gender. According to Balashanmugam et al., (2012)1, "Automobile exhaust emission which contains more than 450 different organic chemical compounds either in gaseous or in particulate or in the combined forms contributes to about 60 percent of air pollution in India with the emission loads in Indian urban cities being in the range of thousands of tons per day".
The concentration of particulate matter in the atmosphere, duration of exposure, proximity to air pollutants and the nature of exposure determine the level of ill effects on the human population with its detrimental effect not just on one organ but instead several major organs such as the lungs, heart, brain and eyes thereby imposing a serious public health problem to all, specially the growing children.

According to Bascom et al., (1996) ${ }^{2}$ "Breathing polluted air can lead to acute health problems ranging from cardio respiratory mortality and morbidity to increased prevalence of respiratory symptoms and decrements in lung function. Children to be more vulnerable because 
they are in general more active, spend more time outdoors and have higher ventilation rates than adults". Islam et al., $(2007)^{3}$ has reported "Reduced lung function in children with an increase in risk of asthma".

Trees and plants are known to increase the oxygen level in the atmosphere, purify the air and lower the level of pollutants. According to research presented at the European Respiratory Society International Congress $2017^{4}$ (http://www.rtmagazine.com/2017/09/city-kidsasthma-suffer-less-live-near-park/) "Children with asthma who live in the city may have fewer days with symptoms the closer they live to parks and green spaces". Hence the present study was aimed to examine whether green space in and around the home was associated with PEFR values of school children in Puducherry.

\section{Materials and Methods}

This cross-sectional school based study was carried out among school children (10-14 years) in Puducherry. A total of 1187 children were selected by stratified random sampling method. The study population comprised of boys and girls from both rural and urban setting.

Written consent from the parents/guardian was taken from the children who were willing to participate in the study. Interview schedule was used to elicit information regarding socio-demographic, health status, dietary and lifestyle pattern of the children.

Assessment of Peak Expiratory Flow Rate (PEFR), pulse rate and oxygen saturation of the selected sample using non-invasive devices such as peak flow meter and pulse oximeter was approved by the Ethical Committee of the Institution. After explaining and demonstrating the procedure, PEFR was measured with disposable mouthpiece in a standing position by giving each child 3 manoevers. The highest of the 3 readings was recorded

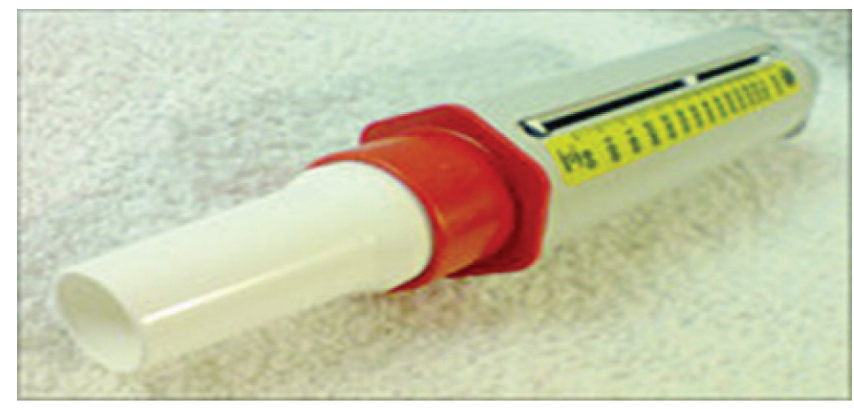

Figure 1. Peak Flow Meter as the PEFR value. Pulse rate and oxygen saturation were measured simultaneously in a sitting position. Data was analyzed using mean and standard deviation.

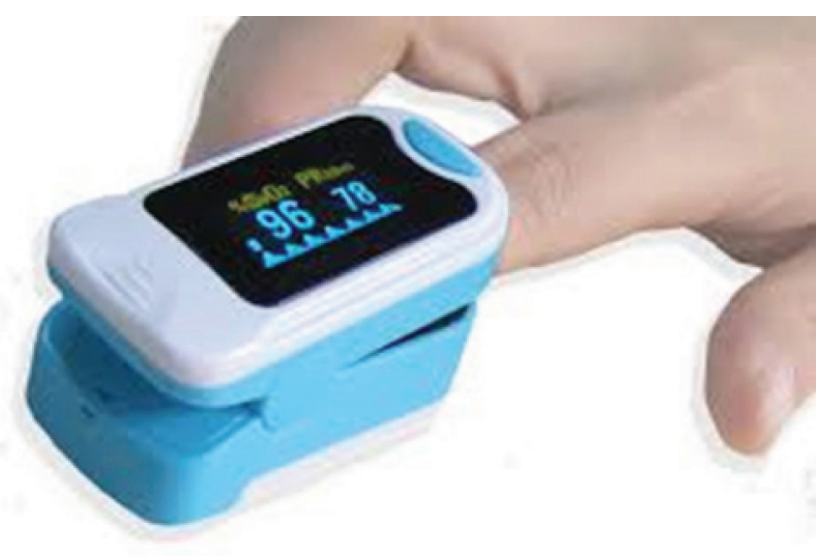

Figure 2. Pulse Oximeter.

\section{Results and Discussion}

A total of 1187 girls and boys (10-14 years) from the rural and urban areas of Puducherry were interviewed and included in the study.

Table 1 shows the overall distribution of the sample based on green cover in and around their home. The overall distribution of girls in the rural (332) and urban area (333) were found to be almost equal whereas the number of boys in the rural area (297) outnumbered those in the urban area (225). The percentage distribution of girls in the rural and urban areas who reported trees and plants in their living space were found to be $94.6 \%$ and $77.5 \%$ respectively. Similar trend was observed in boys with a higher percentage in the rural area (91.6\%) when compared to urban area (83\%).

The association between lung function and the presence of trees and plants in and around their home is illustrated in Table 2. From the above table it is evident that the presence of trees and plants did not have a major positive effect on the $\mathrm{SPO}_{2}$ values of girls and boys in the rural and urban areas. The $\mathrm{SPO}_{2}$ values were found to be above 98 in all the children (belonging to both the groups) except boys (urban area) who had no trees and plants in and around their home. An increase in the pulse rate had been observed in all the children who lived near trees and 
Table 1. Distribution of the Sample Based on Green Cover in and Around the Home

\begin{tabular}{|c|c|c|c|c|c|c|c|c|c|}
\hline \multirow{2}{*}{$\begin{array}{c}\text { Trees and Plants } \\
\begin{array}{c}\text { Surrounding the } \\
\text { Home }\end{array}\end{array}$} & \multicolumn{2}{|c|}{ Rural Girls } & \multicolumn{2}{|c|}{ Urban Girls } & \multicolumn{2}{|c|}{ Rural Boys } & \multicolumn{2}{|c|}{ Urban Boys } & Total \\
\cline { 2 - 9 } & No. & $\%$ & No. & $\%$ & No. & $\%$ & No. & $\%$ & \\
\hline Yes & 314 & 94.57 & 258 & 77.47 & 272 & 91.58 & 187 & 83.11 & 1031 \\
\hline No & 18 & 5.42 & 75 & 22.53 & 25 & 8.42 & 38 & 16.89 & 156 \\
\hline Total & $\mathbf{3 3 2}$ & $\mathbf{1 0 0}$ & $\mathbf{3 3 3}$ & $\mathbf{1 0 0}$ & $\mathbf{2 9 7}$ & $\mathbf{1 0 0}$ & $\mathbf{2 2 5}$ & $\mathbf{1 0 0}$ & $\mathbf{1 1 8 7}$ \\
\hline
\end{tabular}

Table 2. Lung Function Vs. Green Cover in and Around the Home

\begin{tabular}{|c|c|c|c|c|c|c|c|c|}
\hline \multirow{3}{*}{$\begin{array}{c}\text { Lung } \\
\text { Function Test }\end{array}$} & \multicolumn{8}{|c|}{ Mean \pm SD } \\
\hline & \multicolumn{2}{|c|}{ Rural Girls (n=332) } & \multicolumn{2}{|c|}{$\begin{array}{c}\text { Urban Girls } \\
\quad(n=333)\end{array}$} & \multicolumn{2}{|c|}{$\begin{array}{c}\text { Rural Boys } \\
(\mathbf{n}=297)\end{array}$} & \multicolumn{2}{|c|}{$\begin{array}{l}\text { Urban Boys } \\
(n=225)\end{array}$} \\
\hline & Yes & No & Yes & No & Yes & No & Yes & No \\
\hline SPO2 (\%) & $98.5 \pm 1.3$ & $98.7 \pm 1.1$ & $98.4 \pm 1.8$ & $98.2 \pm 2.0$ & $98.3 \pm 2.0$ & $98.4 \pm 1.2$ & $98.3 \pm 1.8$ & $97.8 \pm 2.5$ \\
\hline Pulse Rate & $93.5 \pm 11.2$ & $90.7 \pm 12.2$ & $96.5 \pm 11.9$ & $93.7 \pm 11.7$ & $92.3 \pm 11.0$ & $89.1 \pm 13.1$ & $93.2 \pm 12.7$ & $90.9 \pm 12.3$ \\
\hline $\operatorname{PEFR}(\mathrm{L} / \mathrm{min})$ & $294.7 \pm 53.8$ & $297.2 \pm 49,9$ & $262.1 \pm 59.9$ & $259.3 \pm 58.6$ & $283.9 \pm 71.0$ & $260.0 \pm 52.0$ & $291.9 \pm 68.5$ & $288.4 \pm 56.2$ \\
\hline
\end{tabular}

plants with the difference corresponding to 2.8 each in rural and urban girls while it was 3.2 and 2.3 in rural and urban boys respectively. The $\mathrm{SPO}_{2}$ values and pulse rate were within the normal range for school children (10-14 years) and no association was seen in the group with trees and plants in their homes.

PEFR value of girls and boys from the rural and urban areas with trees and plants in their home were found to be $294.7,262.1,283.9$ and $291.9 \mathrm{~L} / \mathrm{min}$ respectively. Girls living in the rural area $(294.7 \pm 53.8$ Vs. $297.2 \pm 49.9)$ and boys living in the urban area ( $291.9 \pm 68.5$ Vs. $288.4 \pm 56.2)$ had higher PEFR when compared to their counterparts. All the children who had green cover in and around their home had a higher PEFR value (except girls in the rural area whose value was lower by $2.5 \mathrm{~L} / \mathrm{min}$ ) with boys from the rural area showing the highest difference of 23.9 $\mathrm{L} / \mathrm{min}$. The minimum difference in PEFR between the two groups was noted as $2.8 \mathrm{~L} / \mathrm{min}$ (urban girls).

\section{Conclusion}

Trees and plants play a vital role not only in sustenance of life but also in improving the quality of life by increasing the oxygen level in the atmosphere, lowering the air pollution and preventing decrement in lung function caused due to air pollution. Hence, children must be encouraged to spend more time in greenspaces such as parks, backyards and open spaces with more trees and plants and also motivated to start their own kitchen garden and terrace garden. Awareness about the association between trees, plants and respiratory health can be given in schools considering the long term benefits in the quality of life of school children.

\section{References}

1. Balashanmugam P, Ramanathan AR, Nehru Kumar V. (2012). International Journal of Engineering Research and Applications (IJERA). 2012 Mar-Apr; 2(2): 300-7. Available from http://www.ijera.com ISSN: 2248-9622

2. Bascom R, Bromberg P, Costa D, Devlin R, Dockery D, Frampton M, Lambert W, Samet J, Speizer F, Utell M. State of the Art Health Effects of Outdoor Air Pollution. Part 1. Am. J. Respir. Crit. Care Med. 1996. 153: 3-50.

3. Islam T, Gauderman WJ, Berhane K, et al. Relationship between Air Pollution, Lung Function and Asthma in Adolescents. Thorax. 2007; 62: 957-63.

4. City Kids with Asthma Suffer Less if they Live Near a Park. 10 September 2017. Available from: http://www.rtmagazine.com/2017/09/city-kids-asthma-suffer-less-live-nearpark/ 